\title{
Effect of bone graft density on in vitro cell behavior with enamel matrix derivative
}

\author{
Richard J. Miron • Oana M. Caluseru • Vincent Guillemette • \\ Yufeng Zhang • Daniel Buser • Fatiha Chandad • Anton Sculean
}

Received: 16 May 2014 / Accepted: 8 December 2014 / Published online: 18 December 2014

(C) Springer-Verlag Berlin Heidelberg 2014

\begin{abstract}
Objectives Bone replacement grafting materials play an important role in regenerative dentistry. Despite a large array of tested bone-grafting materials, little information is available comparing the effects of bone graft density on in vitro cell behavior. Therefore, the aim of the present study is to compare the effects of cells seeded on bone grafts at low and high density in vitro for osteoblast adhesion, proliferation, and differentiation.

Materials and methods The response of osteoblasts to the presence of a growth factor (enamel matrix derivative, (EMD)) in combination with low (8 $\mathrm{mg}$ per well) or high (100 mg per well) bone grafts (BG; natural bone mineral, Bio$\left.\mathrm{Oss}^{\circledR}\right)$ density, was studied and compared for osteoblast cell adhesion, proliferation, and differentiation as assessed by realtime PCR. Standard tissue culture plastic was used as a control with and without EMD.

Results The present study demonstrates that in vitro testing of bone-grafting materials is largely influenced by bone graft seeding density. Osteoblast adhesion was up to $50 \%$ lower when
\end{abstract}

R. J. Miron $(\bowtie) \cdot$ O. M. Caluseru $\cdot$ V. Guillemette $\cdot$ F. Chandad Faculté de medecine dentaire, Pavillon de médecine dentaire, rue de la Terrasse, Université Laval, Québec, Canada

e-mail: richard.miron@zmk.unibe.ch

R. J. Miron · A. Sculean

Department of Periodontology, University of Bern, Bern,

Switzerland

R. J. Miron · D. Buser

Department of Oral Surgery and Stomatology, School of Dental

Medicine, University of Bern, Bern, Switzerland

Y. Zhang

The State Key Laboratory Breeding Base of Basic Science of Stomatology (Hubei-MOST) \& Key Laboratory of Oral Biomedicine Ministry of Education, School \& Hospital of Stomatology, Wuhan University, Wuhan, China cells were seeded on high-density BG when compared to lowdensity BG and control tissue culture plastic. Furthermore, proliferation was affected in a similar manner whereby cell proliferation on high-density BG (100 mg/well) was significantly increased when compared to that on low-density BG $(8 \mathrm{mg} / \mathrm{well})$. In contrast, cell differentiation was significantly increased on high-density BG as assessed by real-time PCR for markers collagen 1 (Col 1), alkaline phosphatase (ALP), and osteocalcin (OC) as well as alizarin red staining. The effects of EMD on osteoblast adhesion, proliferation, and differentiation further demonstrated that the bone graft seeding density largely controls in vitro results. EMD significantly increased cell attachment only on high-density BG, whereas EMD was able to further stimulate cell proliferation and differentiation of osteoblasts on control culture plastic and low-density BG when compared to highdensity BG.

Conclusion The results from the present study demonstrate that the in vitro conditions largely influence cell behavior of osteoblasts seeded on bone grafts and in vitro testing.

Clinical relevance These results also illustrate the necessity for careful selection of bone graft seeding density to optimize in vitro testing and provide the clinician with a more accurate description of the osteopromotive potential of bone grafts.

Keywords Bone graft · Bio-Oss · Emdogain · Osteogain · Periodontology $\cdot$ Osteoinduction

\section{Introduction}

Bone replacement grafting materials have played an important role in regenerative dentistry for the treatment of bony defects as well as sinus floor augmentations [1]. Their primary goal is to facilitate recruitment of bone-forming osteoblasts (osteoconduction) and increase the production of boneinducing substances to the microenvironment (osteoinduction) 
[2]. A variety of biologic and synthetic materials are available for the surgical treatment of alveolar bone loss. Although autogenous bone graft is considered the gold standard [3], many other materials, including bone allografts, xenografts, and alloplasts, are extensively being studied in order to avoid the drawbacks and limitations of autogenous bone which include donor site morbidity and additional surgical costs [4-10]. As a result, bone substitutes have been developed with the aim of supporting bone regrowth.

In recent years, various bone graft substitutes derived from human (freeze-dried bone allografts (FDBA)), bovine (xenograft), as well as synthetically fabricated alloplasts (hydroxyapatite (HA), beta tricalcium phosphate $(\beta-\mathrm{TCP})$, polymers, and bioactive glasses) have been used for the regeneration of bone in oral surgery with clinical success [11-14]. The additional use of growth factors such as platelet-rich plasma, platelet-derived growth factor (PDGF), and bone morphogenetic proteins (BMPs) has provided further clinical success [15-17]. Of particular interest to the field of dentistry is the commercially available product Emdogain ${ }^{\circledR}$, which is an enamel matrix derivative (EMD) harvested from developing porcine teeth $[18,19]$. EMD was initially developed for the regeneration of the periodontium and has since been used successfully for a variety of clinical applications including intrabony, recession, and furcation defects [20].

Prior to human and animal testing of bone grafts, in vitro research is routinely performed to determine the safety and biocompatibility of each grafting material. To validate its biocompatibility, cell culture systems are utilized to determine graft's ability to support cell adhesion, proliferation, and differentiation. Despite a wide range of tested bone-grafting materials, the effects of bone graft density at the bottom of cell culture plastic dishes on cell behavior are virtually unknown. Therefore, the aim of the present study is to determine the effects of low- and high-density seeding of bone grafting (BG) particles on cell behavior. Furthermore, the response of osteoblasts in the presence of (EMD) in combination with bone grafts seeded at low and high density was studied. A natural bone mineral (NBM) and EMD were chosen as bone-grafting material and growth factor, respectively, due to their widespread clinical use in dentistry as well as our laboratory experience with their handling [21-23]. We hypothesize bone graft density significantly influences osteoblast cell adhesion, proliferation, and differentiation and its ability to respond to EMD.

\section{Methods}

Bone graft density and surface coating with EMD

For all experiments, a natural bone mineral (NBM; Bio-Oss ${ }^{\circledR}$, Geistlich Pharma AG, Wolhusen, Switzerland) was selected due to its widespread use, osteoconductive properties, and surface topography that resembles the human bone (Fig. 1). EMD was prepared according to Institut Straumann AG standard operating protocols as previously described [24]. Thirty milligrams of EMD was dissolved in $3 \mathrm{ml}$ of $4{ }^{\circ} \mathrm{C}$ sterile $0.1 \%$ acetic acid. For experiments, stock EMD was diluted 1:100 in $0.1 \mathrm{M}$ carbonate buffer at $4{ }^{\circ} \mathrm{C}$ giving a working solution of $100 \mu \mathrm{g} / \mathrm{ml}$. For control samples, $1 \mathrm{ml}$ of EMD solution was poured onto each well of 24-well culture plates and incubated overnight at $4{ }^{\circ} \mathrm{C}$. Following incubation, plates were rinsed with $1 \mathrm{ml}$ phosphate buffered saline (PBS) twice at $4^{\circ} \mathrm{C}$. For low-density BG samples (Fig. 2a) and high-density BG samples (Fig. 2b), $1 \mathrm{ml}$ of EMD solution was poured onto 8 and $100 \mathrm{mg}$ of NBM particles, respectively, in wells of 24-well culture plates and incubated overnight at $4{ }^{\circ} \mathrm{C}$. Following incubation, samples were rinsed with $1 \mathrm{ml}$ PBS twice at $4{ }^{\circ} \mathrm{C}$, and these conditions were used for the subsequent cell culture experiments.

\section{Osteoblast cell isolation and differentiation}

Human bone chips were cultured according to an explant model [25] under signed informed consent approved by the Ethics Committee, Canton Bern, Switzerland, as previously described [21]. Primary human alveolar osteoblasts from three donors not demonstrating any signs of periodontal disease were detached from the tissue culture plastic using trypsin solution (Invitrogen, Basel, Switzerland). Cells used for experimental seeding were from passages 4-6. During cell seeding, $\alpha$-MEM medium was supplemented with $50 \mu \mathrm{g} / \mathrm{ml}$ ascorbic acid and $2 \mathrm{mM} \beta$-glycerophosphate to promote osteoblast differentiation. Primary osteoblasts were seeded on bone grafts at a density of 10,000 cells in 24-well culture plates (Falcon, Franklin Lakes, NJ, USA) for cell attachment and cell proliferation experiments and 50,000 cells for realtime PCR and alizarin red experiments. For experiments lasting longer than 5 days, medium was replaced twice weekly.

\section{Adhesion and proliferation assays}

Primary osteoblasts were seeded on low-density BG ( $8 \mathrm{mg}$ / well) and high-density BG (100 mg/well) coated with or without EMD in wells of 24-well plates at a density of 10, 000 cells per well. Empty wells (without any coated material) were seeded with cells in the presence or absence of EMD and constituted the tissue culture plastic controls. Cells were quantified using measurement of DNA at 4 and $8 \mathrm{~h}$ for cell adhesion and 1,3, and 5 days for cell proliferation. At desired time points, cells were washed with PBS and lysed by ultrasonic homogenization in $400 \mu \mathrm{l}$ of $0.1 \%(v / v)$ Triton X-100 (Sigma-Aldrich, Basel, Switzerland). The DNA contents of the cell extracts were determined using a commercial kit including the fluorescent dye PicoGreen (Quant-iT, Invitrogen) under standard protocol. Fluorescent readings 
Fig. 1 SEM images of NBM particles at low (a) and high magnification (b). Control noncoated NBM particles display a wide range of large

macrotopographies (a) with the presence of many

nanotopographies resembling the appearance of the bone (b)
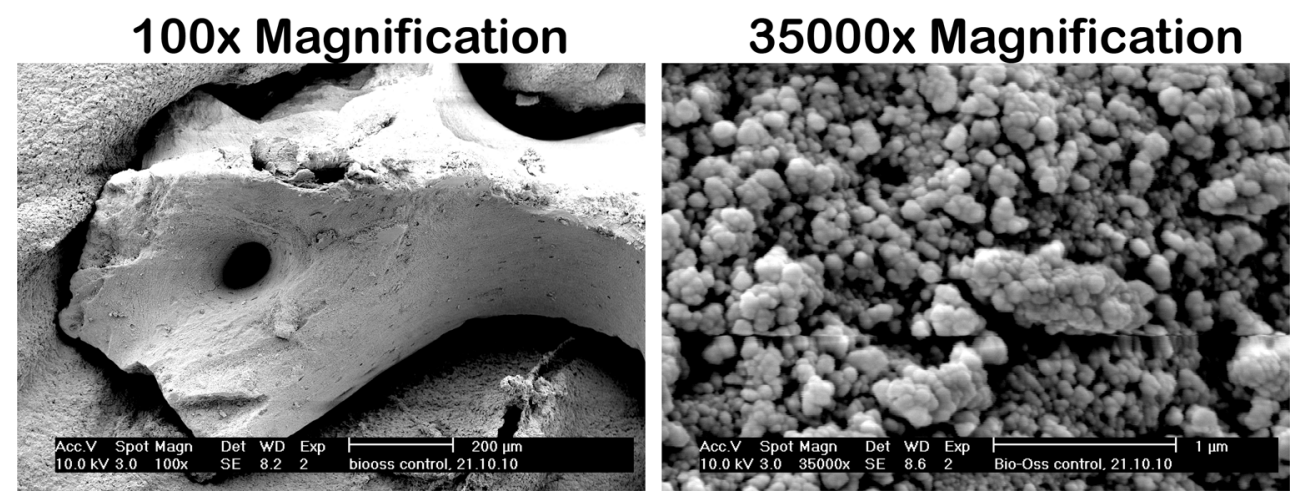

were performed on an Infinite 200 microplate reader (Tecan Group Ltd. Männedorf, Switzerland) at an excitation wavelength of $480 \mathrm{~nm}$ and an emission reading of $520 \mathrm{~nm}$. Experiments were performed in triplicate with three independent experiments for each condition. Data were analyzed for statistical significance using two-way analysis of variance with Bonferroni test.

\section{Real-time RT-PCR}

Total RNA was isolated using TRIzol reagent and RNeasy Mini Kit (QIAGEN, Basel, Switzerland) at time points 3 and 14 days for osteoblast differentiation markers. Primer and probe sequences for genes encoding alkaline phosphatase (ALP; Hs01029144_m1), runt-related transcription factor 2 (Runx2; Hs00231692_m1), collagen $1 \alpha 1$ (COL1A1; Hs01028970_m1), osteocalcin (OC; Hs01587814_g1), and glyceraldehyde 3-phosphate dehydrogenase (GAPDH; Hs03929097_g1) were purchased as pre-designed gene expression assays (Applied Biosystems, Basel, Switzerland). Real-time RT-PCR was performed using $20 \mu \mathrm{l}$ final reaction volume of TaqMan ${ }^{\circledR}$ 's One-step Master Mix kit. RNA quantification was performed using a NanoDrop 2000c with $100 \mathrm{ng}$ of total RNA that was used per sample well. All samples were assayed in triplicate, and three independent experiments were performed. The $\Delta \Delta \mathrm{Ct}$ method was used to calculate gene expression levels normalized to GAPDH values and calibrated to control samples without additional EMD at 3 days. Data were log transformed prior to analysis by two-way ANOVA with Bonferroni test using GraphPad Software v. 4 (GraphPad Software, La Jolla, CA, USA).

\section{Alizarin red quantification}

Alizarin red staining was performed to determine the presence of extracellular matrix mineralization after 21 days. Osteoblasts were seeded at a density of 50,000 cells per well onto plastic control, low-density BG, and high-density BG coated with/without EMD. After 21 days, cells were fixed in $96 \%$ ethanol for $15 \mathrm{~min}$ and stained with $0.2 \%$ alizarin red solution in water ( $\mathrm{pH}$ 6.4) at room temperature for $1 \mathrm{~h}$. Alizarin red was dissolved using a solution of $20 \%$ methanol and $10 \%$ acetic acid in water for $15 \mathrm{~min}$. Liquid was then transferred to cuvettes and read on a spectrophotometer at a wavelength of $450 \mathrm{~nm}$. After subtraction of background, absorbance values were normalized to DNA content and to control bone grafts. Data were analyzed for statistical significance using one-way analysis of variance with Tukey's test.
Fig. 2 Demonstration of bone grafts (BG) placed in the bottom of a 24-well culture dish at a low and $\mathbf{b}$ high density. While a large number of cells are able to attach to tissue culture plastic at low density, placement of $100 \mathrm{mg}$ of NBM particles per 24-well entirely covers the tissue culture plate making it mandatory for cells to attach to BG particles
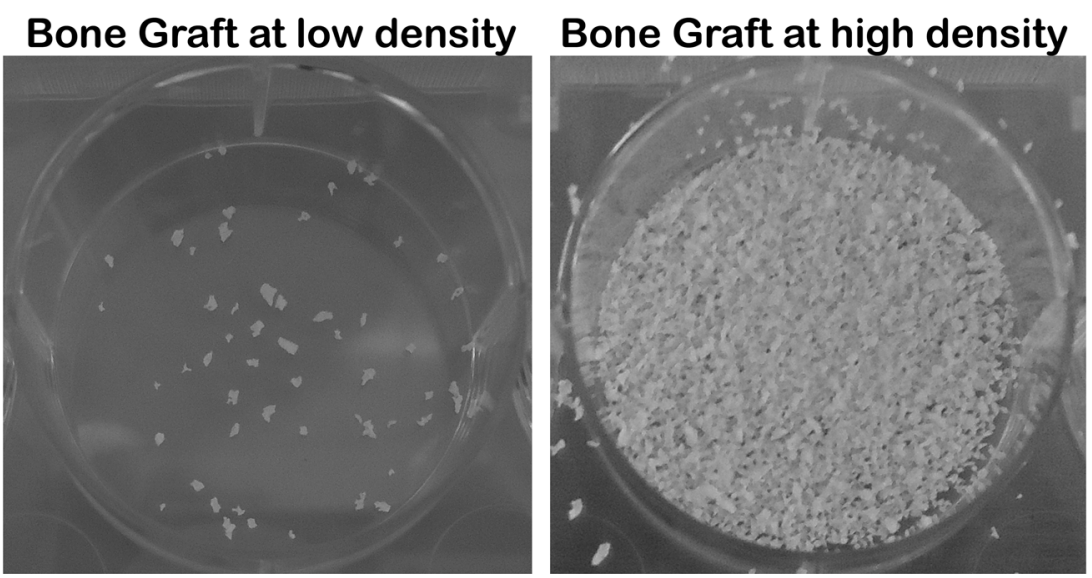


\section{Results}

\section{Osteoblast cell attachment}

Primary human osteoblasts were attached on all control, lowdensity BG, and high-density BG irrespective of EMD coating (Fig. 3). Osteoblasts seeded on plastic control surfaces demonstrated cell adhesion of $96.3 \%$ without EMD and $98.3 \%$ with EMD at $4 \mathrm{~h}$ post seeding (Fig. 3). A similar observation was viewed with osteoblasts seeded on low-density BG irrespective of EMD coating. Interestingly, osteoblast cell attachment was significantly higher on EMD-coated BG particles at both 4 and $8 \mathrm{~h}$ in the high-density BG group (Fig. 3). At $4 \mathrm{~h}$ post seeding on high-density BG particles without EMD, only $47.1 \%$ of osteoblast attachment was observed versus $85.2 \%$ on high-density BG particles with EMD (Fig. 3). At 8 h post seeding, cell attachment increased by 54.8 and $89.9 \%$ for high-density BG without versus with EMD, respectively. Cell attachment was significantly lower on high-density BG particles when compared to all other groups (Fig. 3, \#p<0.05).

\section{Osteoblast cell proliferation}

Primary human osteoblasts displayed various rates of cell proliferation for control, low-density BG, and high-density BG (Fig. 4). For osteoblasts seeded on control culture plastic wells, EMD was able to significantly increase cell proliferation by 51 and $59 \%$ at 3 and 5 days post seeding, respectively (Fig. 4). Similarly, osteoblasts seeded on low-density BG were able to stimulate cell proliferation by 59 and $60 \%$ when coated with EMD at 3 and 5 days post seeding (Fig. 4).

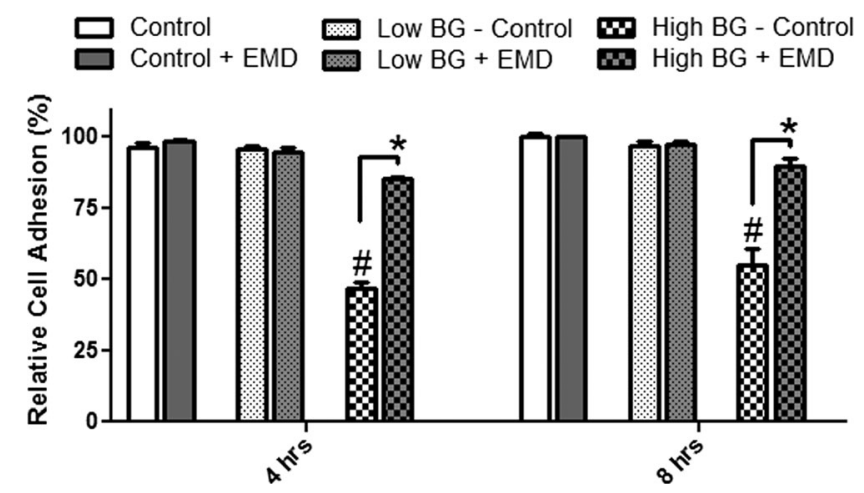

Fig. 3 Adhesion assay of 10,000 primary human osteoblasts seeded on control tissue culture plastic, low-density seeding of bone grafts, and high-density seeding of bone grafts with and without EMD. Relatively, all osteoblasts seeded on tissue culture plastic and low-density bone grafts were able to adhere at 4 and $8 \mathrm{~h}$ post seeding. EMD significantly improved osteoblast attachment at 4 and $8 \mathrm{~h}$ when seeded on highdensity BG particles $(* p<0.05)$. Osteoblasts seeded on high-density BG not containing EMD adhered significantly less when compared to all other treatment groups $(\# p<0.05)$. Data is means \pm SE. $n=9$ samples from three independent experiments
Interestingly, cells seeded on high-density BG displayed significantly lower cell proliferation when compared to control uncoated cell culture samples irrespective of EMD. Furthermore, the effects of EMD only partially stimulated cell proliferation by $34 \%$.

\section{Osteoblast cell differentiation}

To quantify osteoblast differentiation, real-time PCR was utilized for quantification of expression of genes encoding ALP, Col1, Runx2, and OC (Fig. 5). A significant increase was observed in ALP messenger RNA (mRNA) expression for plastic control and low-density BG particles pre-coated with EMD when compared to their respective control samples at 3 and 14 days post seeding (Fig. 5a). Control high-density BG particles demonstrated significantly higher ALP mRNA expression at both 3 and 14 days when compared to control and low-density BG particles for control uncoated samples (Fig. 5a demonstrated by $\# p<0.05$ ). Interestingly, EMD promoted upregulation of ALP on control surfaces by a 3.80- and 2.24-fold increase at 3 and 14 days, respectively, on control surfaces, by 1.65- and 2.04-fold at 3 and 14 days on lowdensity BG samples, and by only 1.26- and 1.47-fold in highdensity BG group (Fig. 5a).

Similar results were observed for mRNA expression of Coll (Fig. 5b). At all times points, EMD significantly increased mRNA levels of control, low-density, and highdensity BG samples when compared to their respective control uncoated samples (Fig. 5b). Again, NBM uncoated particles seeded at high density were able to increase Coll levels by 1.89 - and 1.65-fold when compared to control and lowdensity BG samples at 3 and 14 days, respectively (Fig. 5b). A similar trend was once again observed with respect to EMD coating; EMD was able to upregulate Coll mRNA expression by as much as 2.04-fold on tissue culture plastic whereas EMD increased expression of high-density BG particles by a maximum 1.36-fold increase at 14 days (Fig. 5b).

Runx2 expression demonstrated very consistent results amongst all treatment modalities at all time points (Fig. 5c). No significant difference was observed at any time point, and expression of Runx2 varied slightly between 0.9 - and 1.2-fold the baseline control values at both time points (Fig. 5c).

Coating samples with EMD were most apparent in the upregulation of mRNA expression of OC (Fig. 5d). For control tissue culture plastic, EMD was able to upregulate OC expression by 2.54- and 2.22-fold at 3 and 14 days post seeding, respectively (Fig. 5d). Similarly, EMD was able to stimulate OC mRNA levels by 2.38 - and 1.77-fold on lowdensity BG samples at 3 and 14 days, respectively (Fig. 5d). In contrast, EMD stimulated OC production in high-density BG samples by 1.32- and 1.33-fold, respectively, at 3 and 14 days. This observation however was dictated by the fact that control of high-density samples demonstrated an average 1.56- and 


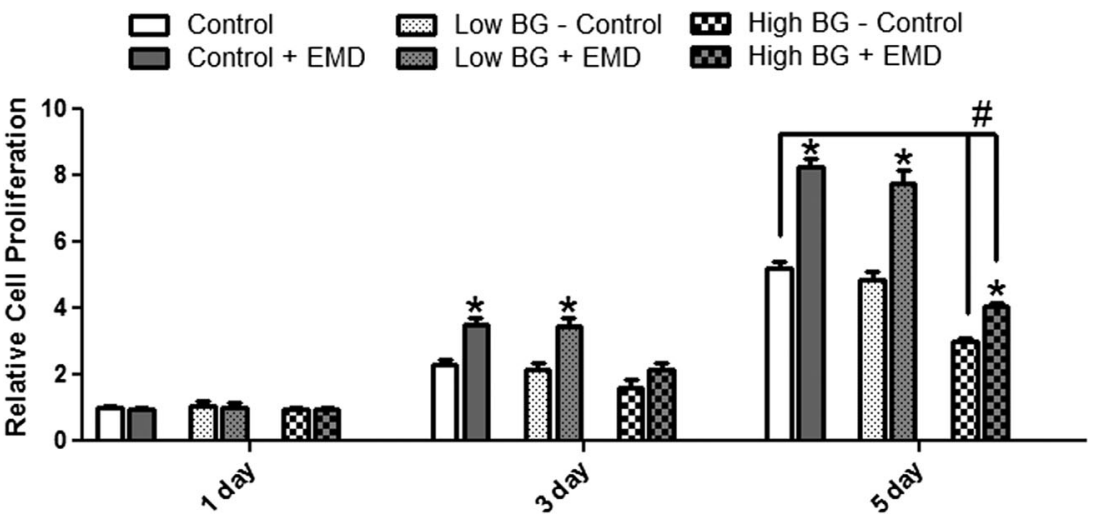

Fig. 4 Proliferation of primary human osteoblasts seeded on control tissue culture plastic, low-density seeding of bone grafts, and highdensity seeding of bone grafts with and without EMD at 1, 3, and 5 days. At 3 days post seeding, EMD significantly increased osteoblast proliferation on culture plastic and low-density BG and however failed to significantly increase proliferation for osteoblasts seeded on high-density
BG. Similar trends were observed at 5 days; however, EMD was then able to significantly increase proliferation on high-density BG at 5 days post seeding when compared to respective controls $\left({ }^{*} p<0.05\right)$. Osteoblasts seeded on high-density BG with and without EMD adhered significantly less when compared to all other treatment groups $(\# p<0.05)$. Data is means \pm SE. $n=9$ samples from three independent experiments 1.41-fold expression of OC when compared to control tissue culture plastic and uncoated low-density BG samples. Interestingly, EMD in control uncoated plastic demonstrated significantly higher expression of OC when compared to EMD+ high-density $\mathrm{BG}$ samples at 3 and 14 days (indicated by $\%$, $p<0.05)$.

Alizarin red staining at 21 days was used to visualize formation of mineralized tissue in vitro (Fig. 6). EMD was able to significantly increase alizarin red staining via normalized absorption at $450 \mathrm{~nm}$ at 21 days for all samples. Furthermore, high-density $\mathrm{BG}$ was able to stimulate significantly higher mineralization when compared to control uncoated tissue culture plastic as well as uncoated low-density BG samples at 21 days (Fig. 6, demonstrated by $\# p<0.05$ ).

\section{Discussion}

In the past 20 years, the development of bone-grafting materials has evolved, and as a result, our understanding of the function and bone-forming ability of various bone grafts has allowed clinicians a broad range of available replacement options. Research designed to determine the ability of osteoconductive scaffolds has largely been tested in vitro prior to clinical and animal studies. Interestingly, however, a wide range of in vitro protocols exists for the design of in vitro testing. The aim of this study was therefore to test the effects of different bone graft seeding densities on the ability for osteoblasts to adhere, proliferate, and differentiate onto bone grafts. The selection of a natural bone mineral (NBM) was selected based on its widespread use in the dental and orthopedic fields as well as our laboratory's previous experience with its handling and in vitro conditions [21, 22]. Similarly, EMD has extensively been used in periodontology for the regeneration of periodontal tissues [20]. Previously, the combination of EMD with a natural bone mineral has been demonstrated to improve periodontal ligament (PDL) and osteoblast adhesion, proliferation, and differentiation in vitro [21, $22]$. For the in vitro experiments presented in this study, the use of NBM as a bone graft in combination with EMD as a growth factor was selected.

Interestingly, many different testing densities for bone grafts have previously been reported ranging from $8 \mathrm{mg}$ per culture well dish to $100 \mathrm{mg}$ and sometimes unreported densities [26-38]. Therefore, the focus of this study was to determine the effects of bone graft density on cell behavior by studying the extremities of reported densities in the literature, that of $8 \mathrm{mg}$ per 24-well dish versus that of $100 \mathrm{mg}$.

The first experiment aimed to determine the effects of highdensity BG in comparison to low-density BG on cell adhesion. Our results revealed that cells adhered significantly less on NBM particles seeded at high density (100 mg bone graft/ well) when compared to all other treatment modalities. This finding demonstrates the drawback in using low-density BG not entirely covering the bottom surface of a culture dish (typically less than $\sim 80 \mathrm{mg} /$ well). Since at low-density BG the cells are essentially able to bind not only to bone grafting particles but also to cell culture plastic, the experimental results do not demonstrate a pure adhesion profile to grafting particles (Fig. 3). For these reasons, a high density presents a more realistic approach for in vitro testing. Furthermore, EMD which has previously been described as a promoting cell adhesion factor [39] was able to rescue in part osteoblast adhesion onto grafting particles seeded at high-density BG whereas EMD had no effect on the cells that were binding to cell culture plastic or low-density BG because their respective controls attached well to plastic (Fig. 3). A similar trend was also observed with respect to the proliferation of osteoblasts on low- and high-density BG (Fig. 4). The proliferation of 
Fig. 5 EMD increases mRNA levels of osteoblast differentiation markers a alkaline phosphatase $(A L P)$, b collagen 1 (COL1), c Runx2, and $\mathbf{d}$ osteocalcin $(O C)$ at various time points. Levels of ALP, COL1, and OC were significantly higher for control tissue culture plastic, low-density $\mathrm{BG}$, and high-density $\mathrm{BG}$ at various time points $\left({ }^{*} p<0.05\right)$. Osteoblasts seeded on control high-density BG produced significantly higher mRNA levels of ALP, COL1, and OC at 14 days post seeding $(\# p<0.05)$. d Interestingly, the increase in osteoblast differentiation markers such as OC by EMD was more pronounced on tissue culture plastic and low-density BG when compared to high-density BG. c No significant differences for Runx2 were observed in osteoblasts at all time points. All experiments were normalized to levels of GAPDH followed by calibration to mRNA levels at day 3 from control tissue culture plastic. Data shown is the average value from three independent experiments (three replicates per experiment $) \pm \mathrm{SE}$
A)

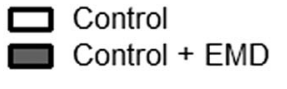

Low BG - Control Low BG + EMD

High BG - Control High BG + EMD

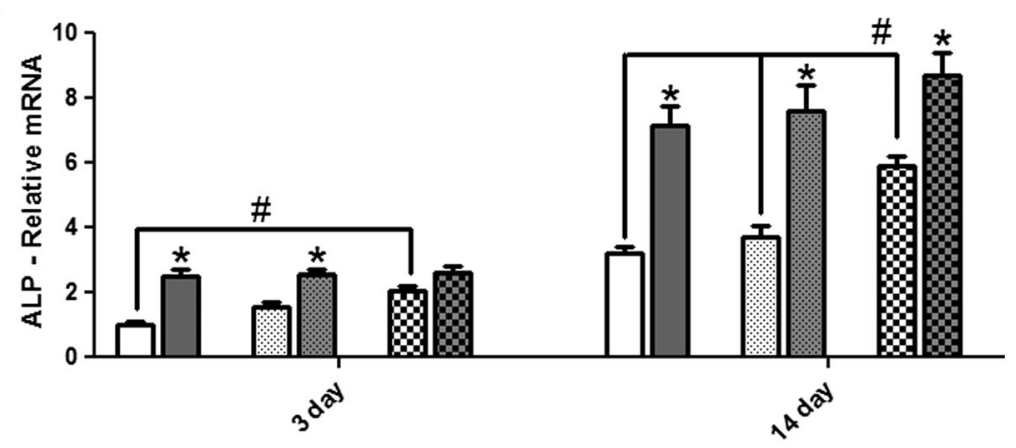

B)
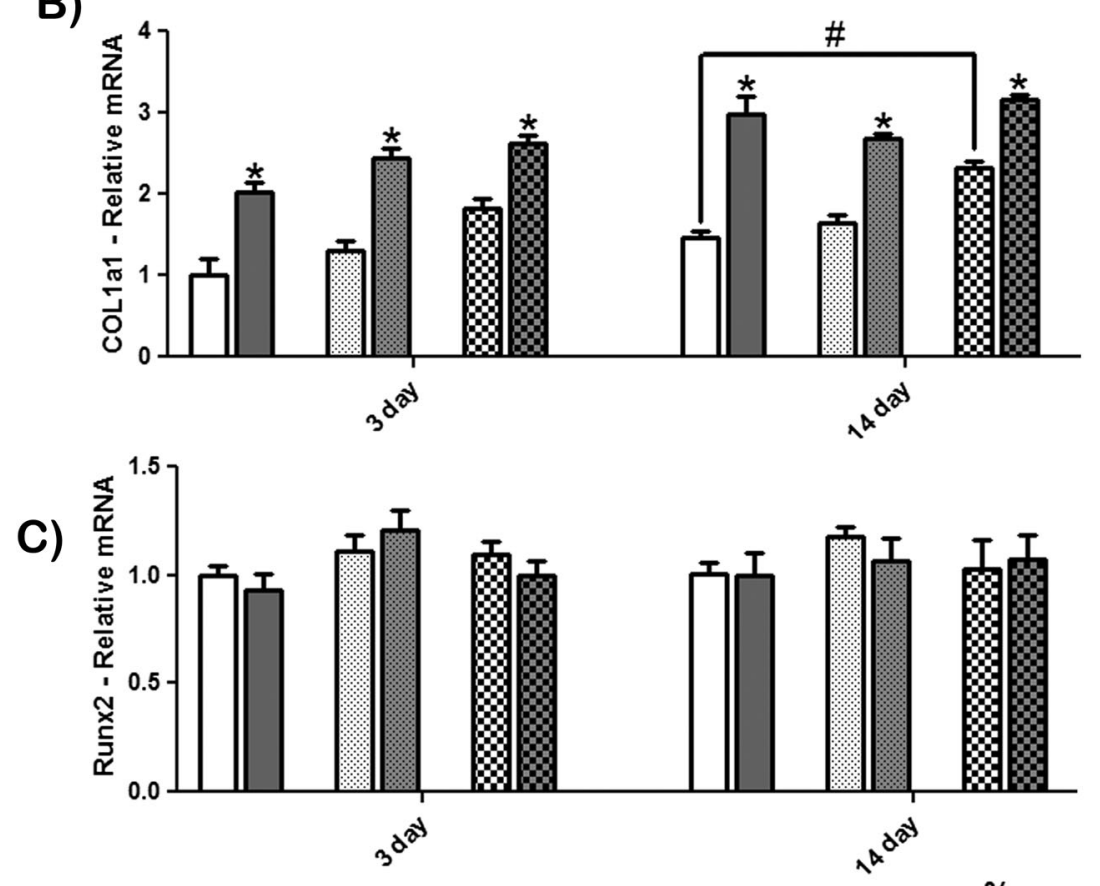

D)

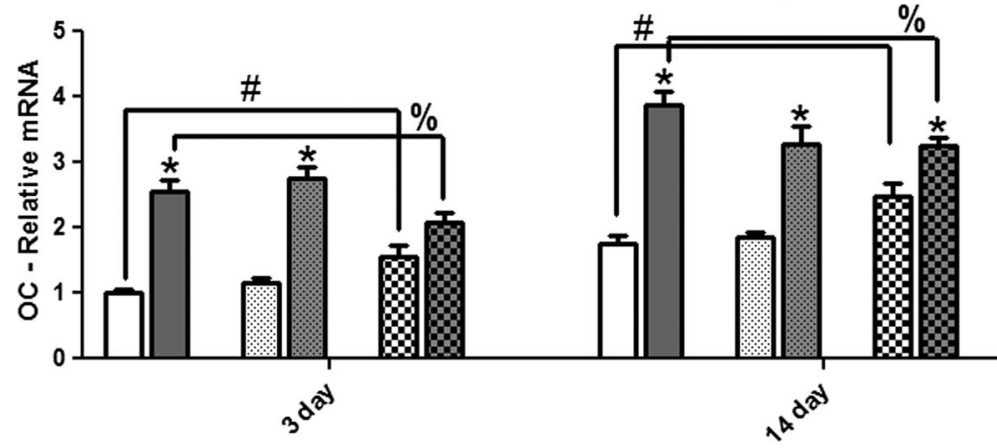

osteoblasts was significantly higher on cells in contact with cell culture plastic again demonstrating the advantages of using high-density BG.

In contrast, cell differentiation was increased for cells seeded on high-density BG when compared to low-density BG and control samples as assessed by alizarin red staining and by real-time PCR (Figs. 5 and 6). In the present study, the housekeeping gene utilized was GAPDH due to its widespread use for in vitro studies using osteoblasts as well as our laboratories' previous handling with its use [3, 22, 36, 40-42]. The total mRNA content was also quantified and corrected using a NanoDrop reader where total RNA and GAPDH values corresponded well. The results from this study also support a high-density BG seeding density as the 


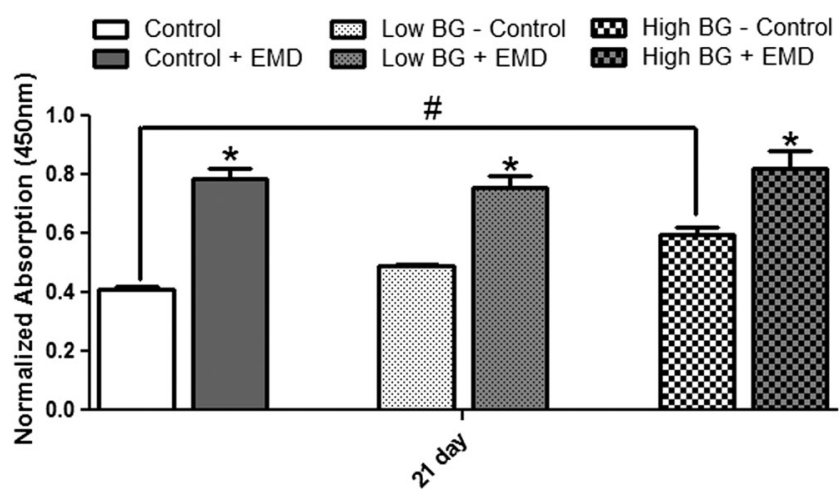

Fig. 6 Normalized alizarin red staining absorbance values at 21 days post seeding. EMD significantly enhanced the ability for cells to undergo mineralization on all tissue culture plastic, low-density BG, and highdensity BG $\left({ }^{*} p<0.05\right)$. Furthermore, osteoblasts seeded on control highdensity BG produced significantly higher levels of alizarin red staining when compared to control tissue culture plastic samples $(\# p<0.05)$

cells seeded on bone grafting particles are able to adapt and interact with the surface topography present on the surface of the grafting particle which simulates an in vivo scenario. Many cells seeded at low-density BG are attaching to cell culture plastic not demonstrating the interaction between bone graft surface topography and cell behavior. It was shown that the osteopromotive effect of EMD was somewhat reduced on high-density BG (Fig. 5) For example, at 3 days post seeding, EMD upregulated ALP mRNA expression by 3.80 -fold on control culture plastic, by 1.65 -fold on low-density BG samples, and by 1.26 -fold in high-density BG group (Fig. 5a). These results suggest that because both bone graft and EMD are both osteopromotive and increase cell differentiation, their combination does not necessarily lead to an additive effect. We have previously demonstrated that EMD affects cell differentiation of osteoblasts via an upregulation of gap junction proteins responsible for cell-cell communication [43]. In this study, the migration of osteoblasts to form cell clusters was a precursor to cell differentiation, and migration of these cells was a vital component. It may be that cells seeded on bone grafts are limited in their cell mobility and ability to migrate due to the surface topography present on NBM particles. Further experiments to investigate this phenomenon are however required.

It was also observed in the present study that Runx2 mRNA levels remained relatively unchanged in osteoblasts but were significantly increased in PDL cells overtime. Other authors have also investigated the influence of EMD on gene expression of Runx2 in osteoblasts overtime and have not observed any significant differences in mRNA levels [24, 44-46]. It has previously been reported by Komori et al. that Runx2 is necessary for early osteoblast differentiation however at later time points is not activated in mature osteoblasts [47]. Given that the primary cells isolated in the present study were isolated from a human alveolar bone which was comprised mainly of differentiated osteoblasts, their ability to express Runx 2 is limited when compared to primary mesenchymal stem cells or PDL cells which comprise a higher percentage of undifferentiated progenitor cells.

It is also important to note that the influence of the bone graft itself in combination with growth factors has a large clinical significance. For example, findings from controlled clinical studies suggest that a combination of EMD and certain types of grafting materials improves the hard and soft tissue parameters compared to treatment with EMD alone or to grafting materials alone [48-53]. Other studies have, however, failed to show statistically significant differences [54-57]. These controversial results suggest that the type of bone graft/bone substitute may influence clinical results and that the technical features, such as particle size, porosity, surface topographies, and chemical composition affect biological behavior [58]. Furthermore, the ability of growth factors to adsorb to various bone-grafting materials could pose challenges as the different topographies and chemistries could influence adsorption to their surfaces.

\section{Conclusion}

The results from these in vitro experiments demonstrate that bone graft seeding density largely affects in vitro cell behavior. Cell adhesion was significantly lower when osteoblasts were seeded on high-density BG when compared to lowdensity $\mathrm{BG}$ and control tissue culture plastic. EMD was only able to significantly increase cell adhesion on high-density BG. Furthermore, proliferation of osteoblasts followed a similar trend whereby a lower proliferation rate for cells seeded on high-density BG was observed when compared to osteoblasts seeded on low density and control tissue culture plastic. In contrast, mRNA expression was significantly higher for genes encoding ALP, COL1, and OC for osteoblasts seeded on highdensity BG when compared to low-density BG as assessed by real-time PCR. The results from the present study illustrate that the in vitro conditions largely influence cell behavior of osteoblasts seeded on bone grafts and in vitro testing. Furthermore, careful selection of bone graft seeding density is necessary to optimize in vitro conditions and provide the clinician with a more accurate description of the osteopromotive potential of bone grafts. The findings of this study can help better design pre-clinical studies and provide more realistic information on graft materials for bone and periodontal regeneration.

Acknowledgments The authors would like to thank Dieter Bosshardt and Reinhard Gruber for their valuable comments with respect to the scientific content of this manuscript.

Conflict of interest No conflict of interest is reported for all authors. The project was funded by the respective institutions: University of Laval, Canada; University of Bern, Switzerland. 


\section{References}

1. Rickert D, Slater JJ, Meijer HJ, Vissink A, Raghoebar GM (2012) Maxillary sinus lift with solely autogenous bone compared to a combination of autogenous bone and growth factors or (solely) bone substitutes. A systematic review. Int J Oral Maxillofac Surg 41:160 167

2. Miron RJ, Zhang YF (2012) Osteoinduction: a review of old concepts with new standards. J Dent Res 91:736-744

3. Miron RJ, Hedbom E, Saulacic N, Zhang Y, Sculean A, Bosshardt DD, Buser D (2011) Osteogenic potential of autogenous bone grafts harvested with four different surgical techniques. J Dent Res 90: 1428-1433

4. Dragoo MR, Sullivan HC (1973) A clinical and histological evaluation of autogenous iliac bone grafts in humans. I. Wound healing 2 to 8 months. J Periodontol 44:599-613

5. Misch CE, Dietsh F (1993) Bone-grafting materials in implant dentistry. Implant Dent 2:158-167

6. Gross, J.S. 1997 Bone grafting materials for dental applications: a practical guide. Compend Contin Educ Dent 18:1013-1018, 10201012, 1024, passim; quiz

7. Hiatt WH, Schallhorn RG, Aaronian AJ (1978) The induction of new bone and cementum formation. IV. Microscopic examination of the periodontium following human bone and marrow allograft, autograft and nongraft periodontal regenerative procedures. J Periodontol 49: 495-512

8. Stahl SS, Froum SJ, Kushner L (1983) Healing responses of human intraosseous lesions following the use of debridement, grafting and citric acid root treatment. II. Clinical and histologic observations: one year postsurgery. J Periodontol 54:325-338

9. Wei, L., Miron, R.J., Shi, B., and Zhang, Y. 2013 Osteoinductive and osteopromotive variability among different demineralized bone allografts. Clin Implant Dent Relat Res

10. Yang, S., Lan, L., Miron, R.J., Wei, L., Zhang, M., and Zhang, Y. 2014. Variability in particle degradation of four commonly employed dental bone grafts. Clin Implant Dent Relat Res

11. Froum, S.J., Tarnow, D.P., Wallace, S.S., Jalbout, Z., Cho, S.C., Rohrer, M.D., and Prasad, H.S. (2005) The use of a mineralized allograft for sinus augmentation: an interim histological case report from a prospective clinical study. Compend Contin Educ Dent 26: 259-260, 262-254, 266-258; quiz 270-251

12. Froum SJ, Wallace SS, Cho SC, Elian N, Tarnow DP (2008) Histomorphometric comparison of a biphasic bone ceramic to an organic bovine bone for sinus augmentation: 6- to 8-month postsurgical assessment of vital bone formation. A pilot study. Int $\mathrm{J}$ Periodontics Restorat Dent 28:273-281

13. Schwartz Z, Weesner T, van Dijk S, Cochran DL, Mellonig JT, Lohmann CH, Carnes DL, Goldstein M, Dean DD, Boyan BD (2000) Ability of deproteinized cancellous bovine bone to induce new bone formation. J Periodontol 71:1258-1269

14. Wallace SS, Froum SJ, Cho SC, Elian N, Monteiro D, Kim BS, Tarnow DP (2005) Sinus augmentation utilizing anorganic bovine bone (Bio-Oss) with absorbable and nonabsorbable membranes placed over the lateral window: histomorphometric and clinical analyses. Int J Periodontics Restorat Dent 25:551559

15. Klongnoi B, Rupprecht S, Kessler P, Thorwarth M, Wiltfang J, Schlegel KA (2006) Influence of platelet-rich plasma on a bioglass and autogenous bone in sinus augmentation. An explorative study. Clin Oral Implants Res 17:312-320

16. Wiltfang J, Schlegel KA, Schultze-Mosgau S, Nkenke E, Zimmermann R, Kessler P (2003) Sinus floor augmentation with beta-tricalciumphosphate (beta-TCP): does platelet-rich plasma promote its osseous integration and degradation? Clin Oral Implants Res $14: 213-218$
17. Stavropoulos A, Wikesjo UM (2012) Growth and differentiation factors for periodontal regeneration: a review on factors with clinical testing. J Periodontal Res 47:545-553

18. Ivanovic A, Nikou G, Miron RJ, Nikolidakis D, Sculean A (2014) Which biomaterials may promote periodontal regeneration in intrabony periodontal defects? A systematic review of preclinical studies. Quintessence Int 45:385-395

19. Miron RJ, Guillemette V, Zhang Y, Chandad F, Sculean A (2014) Enamel matrix derivative in combination with bone grafts: a review of the literature. Quintessence Int 45:475-487

20. Sculean A, Allesandri R, Mrion R, Salvi G, Bosshardt D (2011) Enamel matrix proteins and periodontal wound healing and regeneration. Clin Adv Periodontics 1:101-117

21. Miron, R.J., Bosshardt, D., Hedbom, E., Zhang, Y., Haenni, B., Buser, D., and Sculean, A. 2012. Adsorption of enamel matrix proteins to a bovine derived bone grafting material and its regulation of cell adhesion, proliferation and differentiation. J Periodontol

22. Miron, R.J., Bosshardt, D.D., Zhang, Y., Buser, D., and Sculean, A. (2012) Gene array of primary human osteoblasts exposed to enamel matrix derivative in combination with a natural bone mineral. Clin Oral Investig

23. Miron RJ, Wei L, Bosshardt DD, Buser D, Sculean A, Zhang Y (2014) Effects of enamel matrix proteins in combination with a bovine-derived natural bone mineral for the repair of bone defects. Clin Oral Investig 18:471-478

24. Miron RJ, Oates CJ, Molenberg A, Dard M, Hamilton DW (2010) The effect of enamel matrix proteins on the spreading, proliferation and differentiation of osteoblasts cultured on titanium surfaces. Biomaterials 31:449-460

25. Bennett JH, Carter DH, Alavi AL, Beresford JN, Walsh S (2001) Patterns of integrin expression in a human mandibular explant model of osteoblast differentiation. Arch Oral Biol 46:229-238

26. Acil Y, Springer IN, Broek V, Terheyden H, Jepsen S (2002) Effects of bone morphogenetic protein-7 stimulation on osteoblasts cultured on different biomaterials. J Cell Biochem 86:90-98

27. Ayobian-Markazi N, Fourootan T, Kharazifar MJ (2012) Comparison of cell viability and morphology of a human osteoblast-like cell line (SaOS-2) seeded on various bone substitute materials: an in vitro study. Dent Res J (Isfahan) 9:86-92

28. Behrens P, Wolf E, Bruns J (2000) In vitro culture of human autologous osteoblast cells on natural bone mineral. Orthopade 29:129 134

29. Herten M, Rothamel D, Schwarz F, Friesen K, Koegler G, Becker J (2009) Surface- and nonsurface-dependent in vitro effects of bone substitutes on cell viability. Clin Oral Investig 13:149-155

30. Kubler A, Neugebauer J, Oh JH, Scheer M, Zoller JE (2004) Growth and proliferation of human osteoblasts on different bone graft substitutes: an in vitro study. Implant Dent 13:171-179

31. Liu Q, Douglas T, Zamponi C, Becker ST, Sherry E, Sivananthan S, Warnke F, Wiltfang J, Warnke PH (2011) Comparison of in vitro biocompatibility of NanoBone $\left({ }^{\circledR}\right)$ and BioOss $\left({ }^{\circledR}\right)$ for human osteoblasts. Clin Oral Implants Res 22:1259-1264

32. Liu Y, Lin XP, Tan LS, Wei W (2006) Construction of tissue engineered bone by osteoblasts from canine bone marrow mesenchymal stem cells and Bio-Oss: an in vitro study. Shanghai Kou Qiang Yi Xue 15:627-631

33. Mladenovic Z., Sahlin-Platt A., Andersson B., Johansson A., Bjorn E., and Ransjo M. (2011) In vitro study of the biological interface of Bio-Oss: implications of the experimental setup. Clin Oral Implants Res

34. Payer M, Lohberger B, Stadelmeyer E, Bartmann C, Windhager R, Jakse N (2010) Behaviour of multipotent maxillary bone-derived cells on beta-tricalcium phosphate and highly porous bovine bone mineral. Clin Oral Implants Res 21:699-708

35. Schmitt SC, Wiedmann-Al-Ahmad M, Kuschnierz J, Al-Ahmad A, Huebner U, Schmelzeisen R, Gutwald R (2008) Comparative in vitro 
study of the proliferation and growth of ovine osteoblast-like cells on various alloplastic biomaterials manufactured for augmentation and reconstruction of tissue or bone defects. J Mater Sci Mater Med 19: $1441-1450$

36. Miron RJ, Bosshardt DD, Gemperli AC, Dard M, Buser D, Gruber R, Sculean A (2014) In vitro characterization of a synthetic calcium phosphate bone graft on periodontal ligament cell and osteoblast behavior and its combination with an enamel matrix derivative. Clin Oral Investig 18:443-451

37. Miron RJ, Bosshardt DD, Laugisch O, Dard M, Gemperli AC, Buser D, Gruber R, Sculean A (2013) In vitro evaluation of demineralized freeze-dried bone allograft in combination with enamel matrix derivative. J Periodontol 84:1646-1654

38. Miron RJ, Caluseru OM, Guillemette V, Zhang Y, Gemperli AC, Chandad F, Sculean A (2013) Influence of enamel matrix derivative on cells at different maturation stages of differentiation. PLoS One 8: e71008

39. Hoang AM, Klebe RJ, Steffensen B, Ryu OH, Simmer JP, Cochran DL (2002) Amelogenin is a cell adhesion protein. J Dent Res 81:497500

40. Wang X, Guo B, Li Q, Peng J, Yang Z, Wang A, Li D, Hou Z, Lv K, Kan G et al (2013) miR-214 targets ATF4 to inhibit bone formation. Nat Med 19:93-100

41. Nakashima T, Hayashi M, Fukunaga T, Kurata K, Oh-Hora M, Feng JQ, Bonewald LF, Kodama T, Wutz A, Wagner EF et al (2011) Evidence for osteocyte regulation of bone homeostasis through RANKL expression. Nat Med 17:1231-1234

42. Fukuda T, Takeda S, Xu R, Ochi H, Sunamura S, Sato T, Shibata S, Yoshida Y, Gu Z, Kimura A et al (2013) Sema3A regulates bonemass accrual through sensory innervations. Nature 497:490-493

43. Miron RJ, Hedbom E, Ruggiero S, Bosshardt DD, Zhang Y, Mauth C, Gemperli AC, Iizuka T, Buser D, Sculean A (2011) Premature osteoblast clustering by enamel matrix proteins induces osteoblast differentiation through up-regulation of connexin 43 and $\mathrm{N}$-cadherin. PLoS One 6:e23375

44. He J, Jiang J, Safavi KE, Spangberg LS, Zhu Q (2004) Emdogain promotes osteoblast proliferation and differentiation and stimulates osteoprotegerin expression. Oral Surg Oral Med Oral Pathol Oral Radiol Endod 97:239-245

45. Reseland J.E., Reppe S., Larsen A.M., Berner H.S., Reinholt F.P., Gautvik K.M., Slaby I., and Lyngstadaas S.P. (2006) The effect of enamel matrix derivative on gene expression in osteoblasts. Eur J Oral Sci 114 Suppl 1:205-211; discussion 254-206, 381-202

46. Weishaupt P, Bernimoulin JP, Trackman P, Hagewald S (2008) Stimulation of osteoblasts with Emdogain increases the expression of specific mineralization markers. Oral Surg Oral Med Oral Pathol Oral Radiol Endod 106:304-308
47. Komori T (2006) Regulation of osteoblast differentiation by transcription factors. J Cell Biochem 99:1233-1239

48. Guida L, Annunziata M, Belardo S, Farina R, Scabbia A, Trombelli L (2007) Effect of autogenous cortical bone particulate in conjunction with enamel matrix derivative in the treatment of periodontal intraosseous defects. J Periodontol 78:231-238

49. Kuru B, Yilmaz S, Argin K, Noyan U (2006) Enamel matrix derivative alone or in combination with a bioactive glass in wide intrabony defects. Clin Oral Investig 10:227-234

50. Velasquez-Plata D, Scheyer ET, Mellonig JT (2002) Clinical comparison of an enamel matrix derivative used alone or in combination with a bovine-derived xenograft for the treatment of periodontal osseous defects in humans. J Periodontol 73:433-440

51. Lekovic V, Camargo PM, Weinlaender M, Nedic M, Aleksic Z, Kenney EB (2000) A comparison between enamel matrix proteins used alone or in combination with bovine porous bone mineral in the treatment of intrabony periodontal defects in humans. J Periodontol $71: 1110-1116$

52. Zucchelli G, Amore C, Montebugnoli L, De Sanctis M (2003) Enamel matrix proteins and bovine porous bone mineral in the treatment of intrabony defects: a comparative controlled clinical trial. J Periodontol 74:1725-1735

53. Gurinsky BS, Mills MP, Mellonig JT (2004) Clinical evaluation of demineralized freeze-dried bone allograft and enamel matrix derivative versus enamel matrix derivative alone for the treatment of periodontal osseous defects in humans. J Periodontol 75:1309-1318

54. Hoidal MJ, Grimard BA, Mills MP, Schoolfield JD, Mellonig JT, Mealey BL (2008) Clinical evaluation of demineralized freeze-dried bone allograft with and without enamel matrix derivative for the treatment of periodontal osseous defects in humans. J Periodontol 79:2273-2280

55. Sculean A, Pietruska M, Arweiler NB, Auschill TM, Nemcovsky C (2007) Four-year results of a prospective-controlled clinical study evaluating healing of intra-bony defects following treatment with an enamel matrix protein derivative alone or combined with a bioactive glass. J Clin Periodontol 34:507-513

56. Bokan I, Bill JS, Schlagenhauf U (2006) Primary flap closure combined with Emdogain alone or Emdogain and Cerasorb in the treatment of intra-bony defects. J Clin Periodontol 33:885-893

57. Jepsen S, Topoll H, Rengers H, Heinz B, Teich M, Hoffmann T, AlMachot E, Meyle J, Jervoe-Storm PM (2008) Clinical outcomes after treatment of intra-bony defects with an EMD/synthetic bone graft or EMD alone: a multicentre randomized-controlled clinical trial. J Clin Periodontol 35:420-428

58. Al Ruhaimi KA (2001) Bone graft substitutes: a comparative qualitative histologic review of current osteoconductive grafting materials. Int J Oral Maxillofac Implants 16:105-114 